Historic, Archive Document

Do not assume content reflects current scientific knowledge, policies, or practices. 

ALI5B

BULLEIN NO. 30 EXPERIMENT STATION

TUSKEGEE

FORIAL AND INDUSTRIAL INSTITUTE TUSKEGEE INSTITOE ALABAMA

\section{POSSIBILITIES OF THE SWEET POTATO IN MACON COUNTY ALABAMA}

REVISYD AND REPRNTED

BY GEO. W. CARVER, M. S. AGR.

LIBRARY FOOD ADMINISTRATION TOOOO CONSERVATI N SECTI N. 
Printed by Tuskegee Students from Funds supplied by the Ash Fund, established in memory of Mrs. Ellen L. Ash 


\section{POSSIBILITIES OF THE SWEET POTATO IN MACON COUNTY, ALABAMA}

BY G. W. CARVER, M. S. AGR.

If there is one crop more than another, that Macon County can produce year by year and with almost unerring certainty, it is the sweat potato crop.

Now what is true of Macon County is true of the adjoining counties, and is more or less true of the entire South.

\section{History}

It is said that the early navigators of the sixteenth century recognized such a strong resemblance between the Irish potato and the sweet potato that they called them both by the same name.

They are not only different botanically, but the edible parts of each are in character and taste quite unlike.

Botanically, the sweet potato belongs to the morning glory family (Convolvulaceae), and has been given the technical name of Ipomeabatatas.

\section{Origin}

The origin of the sweet potato is doubtful, although there is very strong evidence that it is distinctly-American, as fifteen or sixteen known species of the genus Batatas are found in this country. The "Indian potato," "Tuckahoe" and "Hog potato," which grow abundantly in this country and throughout the South, are all species of this genus.

\section{Varieties}

More than 100 so-called varieties make up the present list, many of which there is a distinction without a well-defined difference.

Since some varieties do well in one section and practically fail in others, I have thought wise to list none except those that have proven the most prolific and best with us.

TABLE VARIETIES: Dooley Yam, Improved Dooley Yam, Triumph and Pumpkin Yam.

VARIETIES FOR FEEDING STOCK: These grow to a very large size and make a fine yield, but are not very sweet and rather inferior for table use-White Bermuda, Red Nansemond, "Negro Choker" and Hayti Spanish.

\section{Climate and Soil}

As to climate, the sweet potato thrives and does its best only in a warm climate, with plenty of sunshine and moderate showers, 
evenly distributed throughout the growing season. In this, Macois County is especially favored.

The soil, for the most part, is considered a light grey, with an admixture of sand, varying from 11 to 85 per cent, and seems especially adapted to the growing of not only large yields, but potatoes of exceptionally fine flavor.

Heavy, waxy, clay soils are not conducive to heavy yields of potatoes, but fortunately there is but very little soil of this kind in the county.

\section{Selecting the Seed}

Experiments seem to indicate that very large potatoes are not preferable for seed, but those measuring from an inch to an inch and a half in diameter-they should be smooth, long or round as the variety suggests, and free from any woody or stringy appearance. Discard any having specks of decay or that have blemishes of any kind. Also select seed from those hills that show the largest percentages of marketable potatoes, the best flavor, the richest color and the largest yield.

\section{The Plant Bed}

Select as warm and sunny a place as possible; further protect'by banking up on the north side with earth.

Build an ordinary plank cold-frame from 5 to 6 feet wide and any length desired, facing and sloping toward the south, having its south wall several inches lower than its north wall.

Bank up well on the outside, and protect from water by running a little ditch around on the outside. Remove the earth within the frame to a depth of from 4 to 12 inches; spread a thin layer of oak leaves or pine straw on the bottom of this excavation. Upon this place a layer of manure, from 4 to 6 inches thick, and pound down slightly. Place a laver of soil over this, from 2 to 3 inches thick. On this lay the sweet potatoes side by side, horizontally, and just far enough away to keep them from touching each other. Cover with good rich garden soil to a depth of 2 or 3 inches; cover with sash or canvas oiled with linseed or cotton seed oil.

The amount of manure required in the hot bed is governed solely by the climate, more being needed in cold than in warm climates. In the Gulf States, from 2 to 5 inches is the truck gardeners' rule, while 10 and 12 inches is not uncommon in Iowa, Kansas and New Jersey. Keep the bed moist at all times. It requires from 5 to 6 weeks to produce slips large enough for setting.

The sweet potato plant is very susceptible to frost, and should not be planted in large acreages earlier than April 15th. When the plants are 3 or five inches in length and properly hardened off, they are ready to set. 
Ninety days after transplanting is an old rule, but we have been able to get potatoes as large as goose eggs, from the earliest varieties, in 70 days.

\section{Vine Cutting}

It is generally conceded that after the vines have begun to run well, the cuttings are far more preferable than the slips. Several stations have devoted considerable time to this important problem and found that under favorable conditions there is practically no difference in the yield. They, did, however, find that a close pruning of the vines decreased the amount of marketable potatoes by increasing the number of small ones.

This station verified the above in 1908 and 1909.

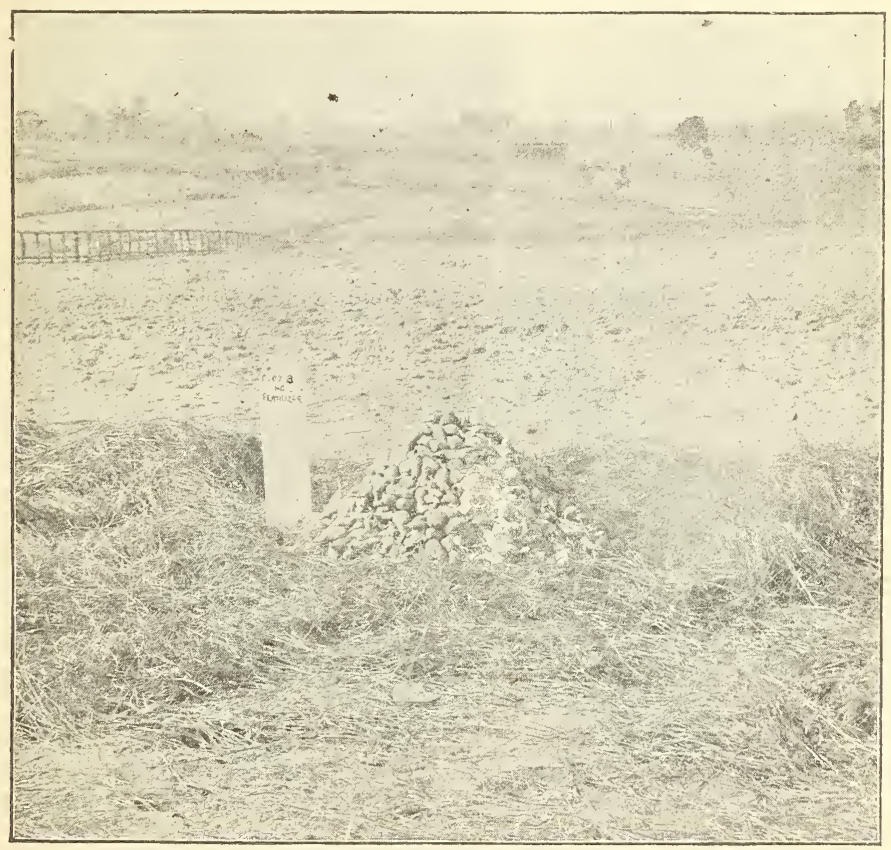

RESULTS OF LAND POORLY PREPARED

\section{Preperation of Land}

In this county the land should be broadcasted to a depth of 9 or 10 inches. If barnyard manure, muck, leaves, etc., are to be used as a fertilizer, it should be broadcasted and plowed in. Harrow 
repeatedly until the soil is thoroughly pulverized and mixed. If commercial fertilizers are used, apply "in the drill," the same as for cotton.

Ridges from 3 to 6 inches above the valleys should be made by throwing two furrows together with a turning plow. Just before planting the tops of these ridges should be knocked off with a board drag, or something of the sort. In land that is inclined to be wet, cold and clammy (which is quite unfit for large yields of potatoes), make the ridges much higher, 12 inches often beng none too high; the object here is to dry out the ground.

If the largest quantity possible is desired per acre, make the rows 2 1-2 feet in width. Ordinarily the rows are from 3 to $31-2$ feet from center to center.

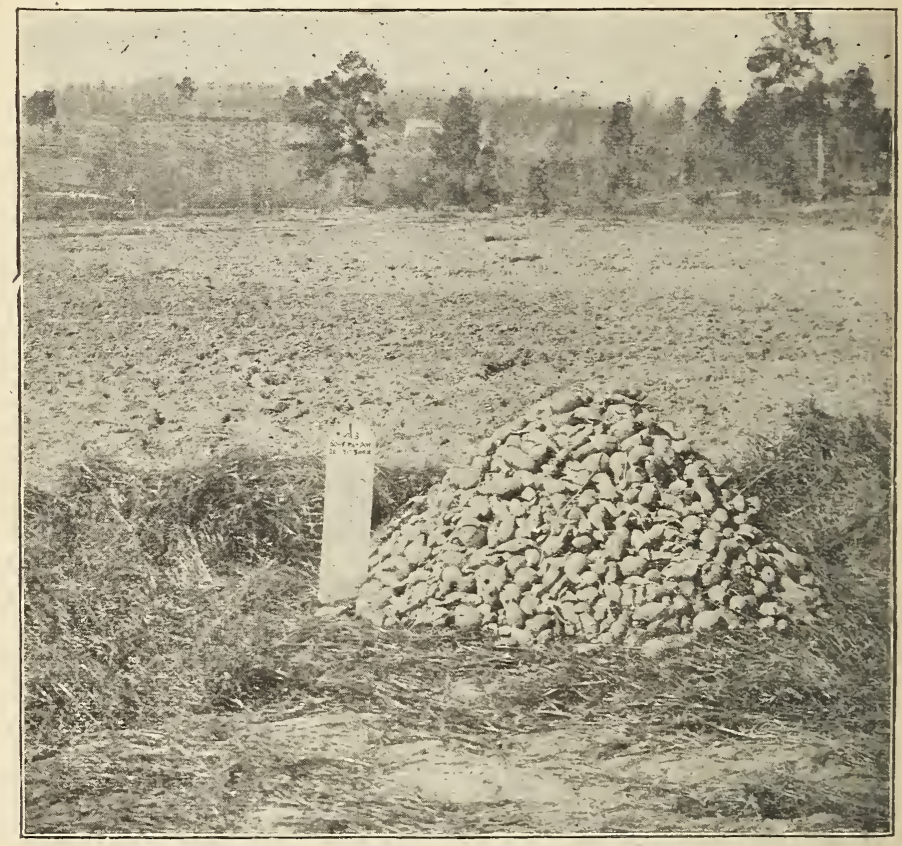

\section{RESULTS OF LAND WELL PREPARED}

\section{Planting}

In setting the plants it is very essential that the ridges be cleaned of weeds-never set plants on a weedy ridge, as it multiplies the work, increases the expense of the crop, and often reduces the yield of potatoes by stunting the growth of the plant. 
In planting set the slips a little deeper than they were in the plant bed. Just after a moderate shower is the most favorable time for setting, although this can be successfully done in very hot, dry weather as follows: (a) By watering the plants, which is tedious and impracticable where large acreages are to be planted. (b) By puddling or mudding the roots, which consists of making a loblolly of thin clay mortar and dipping the roots into it_balls of this moist clay will stick to the roots and stem and, if planted at once, will tide the plant over 9 or 10 days of protracted drought.

\section{Fertilizing}

A series of experiments demonstrated that the grey sandy soils of Macon County respond best to a mixture of 600 pounds of muriate of potash, 120 pounds of acid phosphate, and 75 pounds of nitrate of soda per.acre, making a total of 795 pounds. The application was made exactly the same as for planting cotton, except that only half of the mixture was applied before the plants were set; the other when the plants began to run vigorously. A Ghant fertilizer distributor was used to put the fertilized down each time. The second application of the fertilizers gave the best results, as our soils are leachy, and much of it would have been washed away and probably an equal amount sunken below the depth to which the roots could reach, if all had been put in at one time.

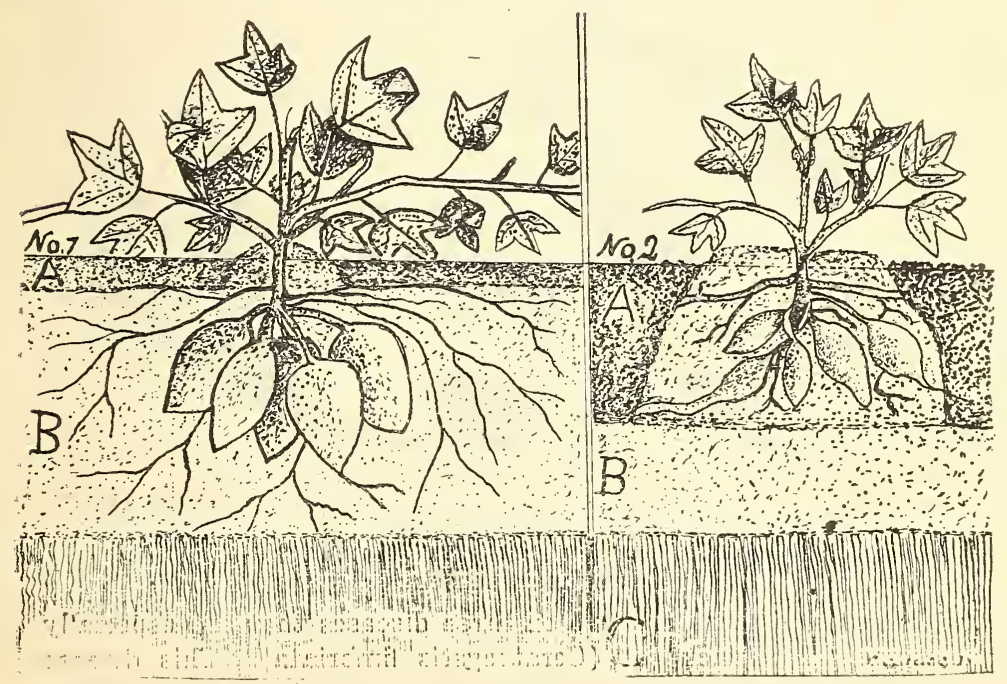

No. 1, Correct Cultivation 
(A) Two inches of fine soil.

(B) Seven inches of loose mellow soil.

(C) Subsoil full of water.

\section{No. 2, Incorrect Cultivation}

(A) Six-inch cultivation, the ground left loose and open.

(B) Three additional inches of loose earth, which will diry out very fast.

(C) Subsoil with its capillary water, much of which will soon be exhausted.

All that is necessary here is to keep the ground free from weeds, and make it loose and porous so that the soil bacteria can get plenty of air, to enable them to do their highest service; also to create and preserve a dust mulch to tide the plants over periods of drought.

The above cut is self-explanatory; it is easily seen that the deep cultivation given in No. 2 has cut the feed roots, and has not only reduced the amount of foliage, but greatly reduced the crop of potatoes.

\section{Insect Enemies}

In this section there are practically no insects that give the farmer trouble-neither cut worms, flea beetles or the Tortoise beetles. The constant stirring of the ground and the vigorous growth sre all against injurious attacks of insects.

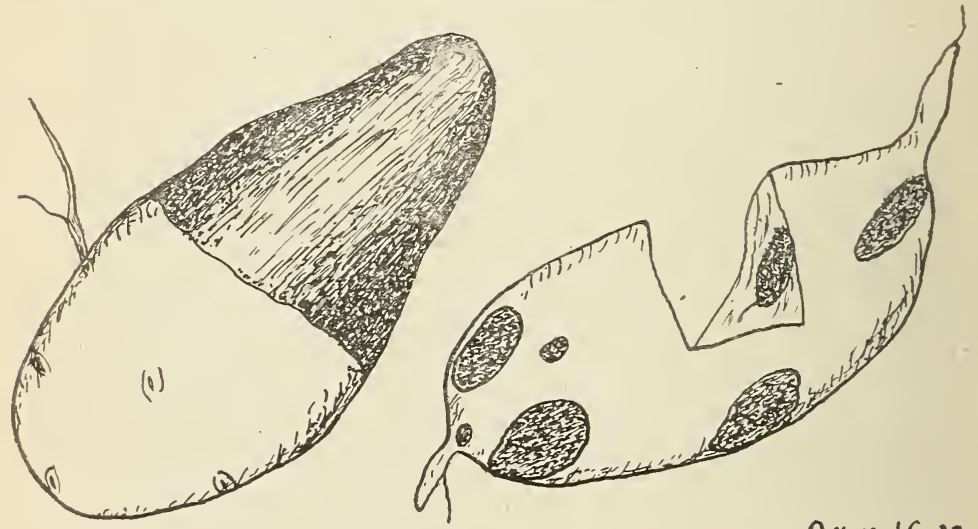

Ceratocystis fimbriata

carvGr-

\section{Fungus Diseases}

In this section there are two or three diseases that are especially troublesome, viz.: black rot (Ceratocystis fimbriata). This disease is especially destructive in the store room. With us, all varieties 
seem to be equally affected. The tubers are more or less marked (according to the severity of the disease) with dark brown patches, which gives the whole tuber an unpleasant bitter taste. If only slightly affected, they bear a strong resemblance, in taste, to frosted potatoes, and for this reason many mistakes are made. It often attacks the plants in the bed, and may be recognized by the plants. turning black at the bottom, and of course such will soon die.

\section{Remedies}

(a) Avoid planting slips from a diseased bed.

(b) Do not save seed from a field containing diseased tubers.

(c) Rotate th crop; do not plant two years in the same place.

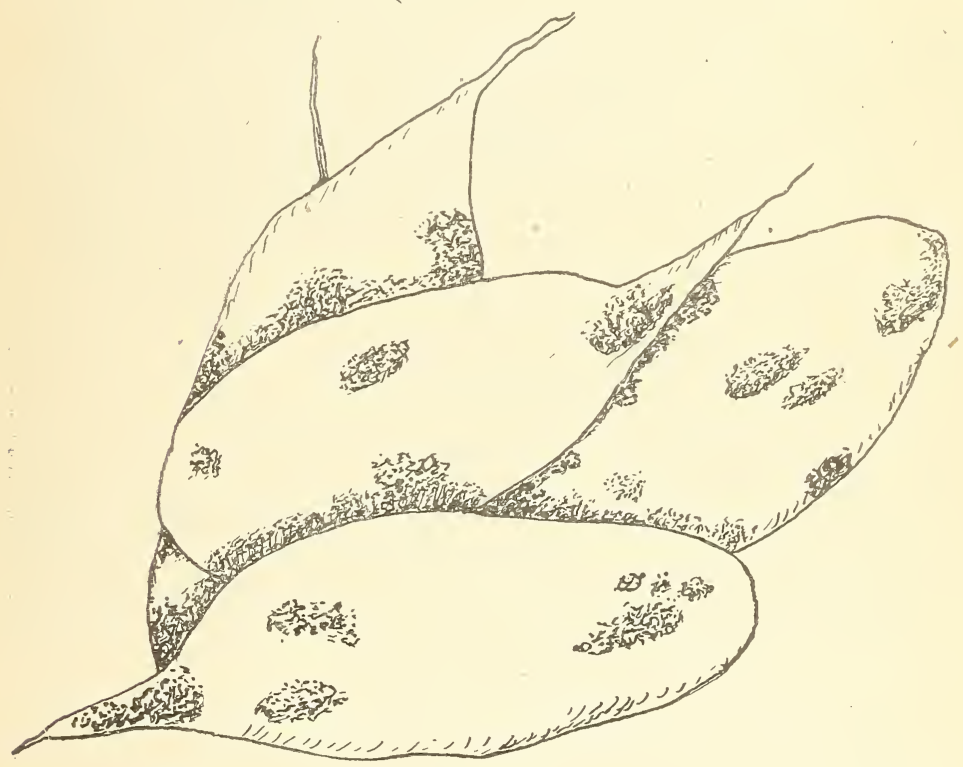

cande.

\section{Soft Rot (Rhizopus nigricans)}

Here, this disease seems to be by far the most troublesome of all, and so far as observation goes, is a storage trouble, being confined strictly to the tubers. It attacks the potato wherever there are bruised, broken or cut places, etc., appearing in black powdery masses like the black mould of bread. Immature, cut, broken and bruised potatoes are harbingers and breeders of the disease. 


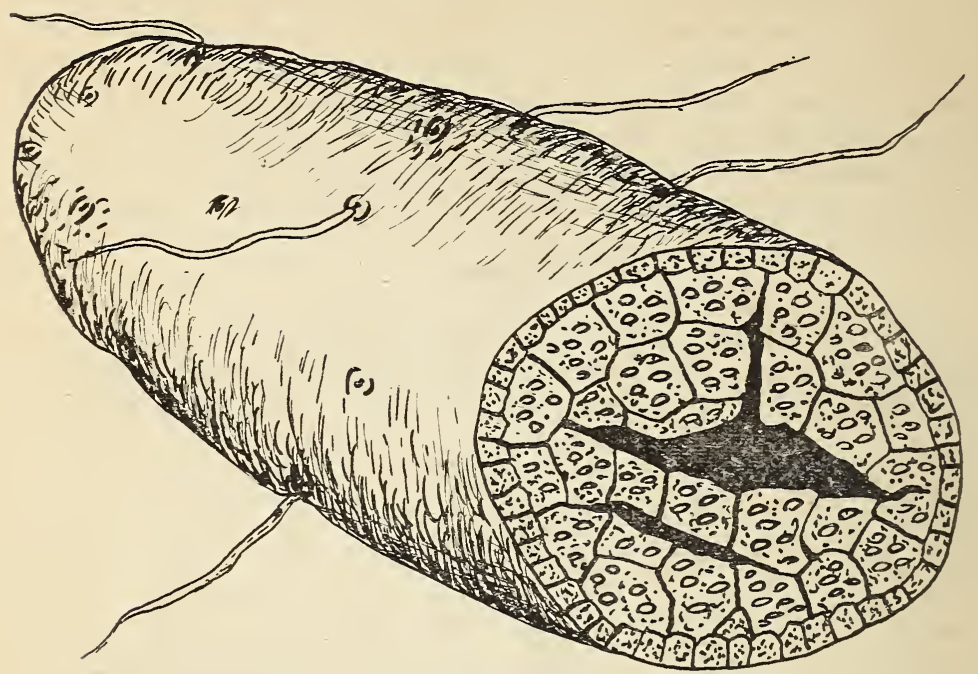

Immature Potato

carjer

Remedies

(a) Nothing but mature potatoes should be banked. (See cut.)

(b) Dry them thoroughly before storing.

(c) Avoid as far as possible the putting in of tubers cut, bruised or injured in any way.

(d) Keep cool and as dry as possible; also free from mice, rats or destructive vermin of any kind.

\section{Harvesting and Storing}

The importance of correctly harvesting the crop is a matter which must not be passed by lightly, as in this lies very largely the success of any method of storing. As far as possible the following should be observed:

(1) Select a time when both the air and ground are dry.

(2) Remove the vines with a sharp hoe, vine cutter or any implement that will do the work rapidly and well.

(3) Dig before the frost injures the vines to any extent. Dig in the morning and allow the potatoes to lie out all day. Gather up in baskets or boxes holding not more than one bushel each. Handle with great care, as they are easily bruised, and every injury lessens their keeping qualities. 


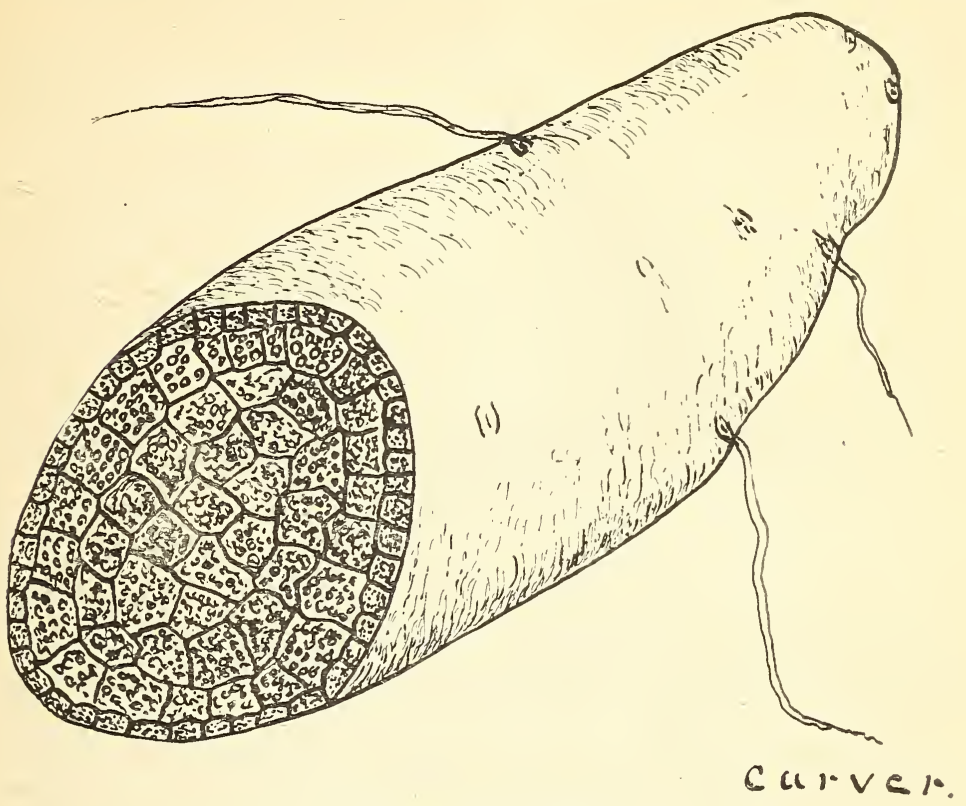

A Mature Potato

In the matter of storing there is a variety of methods, all possessing more or less merit. Where just a few hundred bushels are to be kept, the old primitive method of banking is quite satisfactory. For this a well drained piece of land is selected which is slightly hollowed out-the size of the base of the desired bank. This is covered with leaves, pine-tag, or straw. 


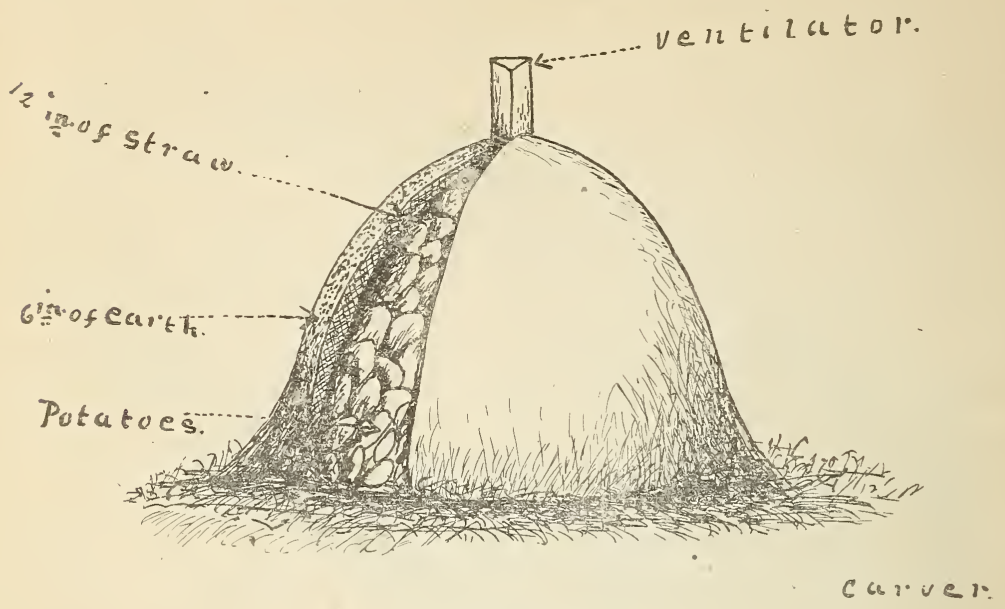

Potato Bank

The potatoes are piled up into a conical shaped mound around a piece of bark curled up, a board flue, or anything that will serve as a ventilator. (See cut.)

The cut shows also the depth to which the straw and earth should be put for this locality. The cover should vary according to the severity of the climate. When large quantities are kept, potato houses seem preferable, as they can at all times be examined and the defective ones removed.

\section{As Food for Man}

As a food for human consumption, the sweet potato has, and always wil be, held in very high esteem, and its popularity will increase as we learn more about its many possibilities.

There is an idea prevalent that anybody can cook sweet potatoes. This is a great mistake, and the many, many dishes of illy cooked potatoes that are placed before me as I travel over the South, prompt me to believe that these recipes will be of value (many of which I have copied verbatim from Bulletin No 129, U. S. Department of Agriculture.) The above bulletin so aptly adds the following:

"The delicate flavor of a sweet potato is lost if it is not cooked properly. Steaming develops and preserves the flavor better than boiling, and baking better than steaming. A sweet potato cooked quickly is not well cooked. Time is an essential element. Twenty minutes may serve to bake a sweet potato so that a hungry man can eat it, but if flavor is an object, it should be kept in the oven an hour." 


\section{No. 1, Boiled or Steamed}

Boil or steam like white potatoes and without breaking the skin. If boiled, pour off the water as soon as done, cover the pot with a cloth and let stand on the back part of the range a few minutes before serving.

\section{No. 2, Baked}

Scrub with a brush and rinse with water until thoroughly clean. Bake like white potatoes, without breaking the skin. When done kreak the skin in one place in the form of a cross, forcing the meat partly out, cap with butter and serve.

Potatoes from 1 to 1 1-2 inches in diameter, and from 5 to 6 inches 'long, are the most desirable for baking-the flavor seems to be far superior to the larger kinds, or the round or irregular sort.

No. 3, Baked in Ashes

In this method the sweetness and piquancy of the potato is brought out in a manner hardly obtainable in any other way. Select the same kind of potatoes as described above for baking; cover them with warm ashes to a depth of 4 inches upon this place live coals and hot cinders; let bake slowly for at least two hours. Remove the ashes with a soft brush, and serve while hot with butter.

\section{No. 4, Fried}

Cut in slices lengthwise and fry in deep grease, same as white potatoes. Care must be taken to not allow them to become hard and dry.

\section{No. 5, Chips}

Cut in thin slices, steam until nearly done, allow the surplus water to drain off or dry between napkins, fry in deep fat to a light brown. This makes a fine breakfast dish. A little salt adds to its flavor.

No. 6, Pie (Extra Fine)

Boil in skins. When tender, remove skins; mash and beat until light. To each pint of potato, add 1-2 pint of milk, 1-2 pint of cream and four well beaten eggs; add 1 1-2 tea-cups of sugar (less if the potatoes are very sweet). Add spice, cinnamon and ginger to taste; one ground clove will improve it. Bake with bottom crust only. The above is enough for five or six pies.

\section{No. 7, Sliced Potato Pie}

Line a deep baking dish with a rich sheet of pastry. Parboil the number of potatoes desired. When two-thirds done remove the skins, slice lengthwise, very thin, cover the dish to a depth of 2 
inches; sprinkle with ground allspice and a dash of ginger, cloves and nutmeg. To a pie sufficient for six people, scatter around the top in small pieces a lump of butter the size of a hen egg;add one teacupful of sugar and 1-2 teacupful of molasses. Add 1-2 pint of cream, dust a little flour over the top sparingly; cover with hot water, put on upper crust, crimp the edges, and bake in a moderate oven until done. Serve hot, with or without sauce.

No. 8, Glace No. 1

Boil and cut in halves medium-sized sweet potatoes, lay evenly in braising pan, baste with syrup and butter warmed together, sprinkle lightly with brown sugar, put in hot oven till brown, and serve in the syrup.

No. 9, Glace No. 2

Cut in slices 1-2 inch thick, wash and place in deep saucepan; spread with butter; season with a little grated nutmeg and salt; moisten with broth or water, cover and let simmer over a slow fire for 3-4 of an hour, turning the slices so that they will glace on both sides. Serve with drawn butter or other sauce.

\section{No. 10, Sweet Potato Cobbler}

Prepare the potatoes the same as for No. 6. Proceed to fill the dish the same as for layer cake, rolling out the layer of dough quite thin and spreading the mixture on in layers about 1-4 of an inch thick. Proceed until the dish is full; add to each layer just enough water to cook the layer of crust. Bake until thoroughly done, and serve hot with drawn butter or hard sauce.

\section{No. 11, With Roast Beef No. 1}

Roast the beef and make a brown gravy. Take sweet potatoes of medium size, previously baked; remove the skin, and garnish the dish with the potatoes. Serve the potatoes with the beef.

\section{No. 13, With Roast Pork}

Parboil the desired number of potatoes with the peelings on until nearly done; remove and peel; lay in the baking dish with the nearly done roast; cook until done, and serve with the beef.

\section{No. 13, With Roast Pork}

Select a desirable piece of fresh pork; bake until nearly done; dip or pour off as much of the grease as possible; prepare the potatoes the same as for No. 12. Lay them in the gravy; and slightly brown, with the meat, until done. 


\section{No. 14, Broiled}

Steam, pare and cut in slices $3-8$ of an inch thick; lay the slices in a double broiler; salt; cover with melted butter, and broil over a slow fire; serve in folded napkins.

\section{No. 15, Stuffed No. 1}

Bake, then cut off one end and scoop out the inside; season with butter, pepper and salt; beat until light; replace in the skin; close with the piece cut off and put into the oven to heat through. Serve in napkins. Suitable for luncheon.

\section{No. 16, Stuffed No. 2}

Prepare the same as for No. 15, to which add to every pint of potato 1-4 pint of minced ham; mix thoroughly, fill the hulls, heat and serve.

\section{No. 17, A Southern Disin}

Cut cold baked sweet potatoes into slices and put into an earthen dish; add sugar and butter to each layer and bake until slightly browned.

\section{No. 18, Croquettes}

Take two cupfuls of mashed, boiled, steamed or baked sweet potatoes; add the beaten yolks of two eggs and season to taste; stir over the fire until the mass parts from the sides of the pan. When cold, form into small croquettes, roll in egg and bread crumbs, and fry in hot lard to amber color. Serve on napkins.

\section{No. 19, Sweet Potato Balls}

Prepare the sauce as for croquettes, make into balls and enclose within the center minced meat.

\section{No. 20, Puree}

Take mashed, boiled, steamed or baked sweet potatoes; season and add enough hot milk to moisten; serve like mashed white potatoes, or put in pudding dish; dress the top with egg and brown in oven; serve with sauce.

\section{No. 21, Browned}

Cut cold, boiled or stewed sweet potatoes into slices 1-4 of an inch thick; add butter, sugar, pepper and salt, and put into hot oven to brown.

\section{No. 22, Scalloped Potatoes}

Wash and peel the potatoes; slice very thin; put in baking dish in layers; season each layer with salt, butter, 1-2 teacup of 
sugar, a dash of spice, nutmeg and ginger; cover with milk that has been made 1-2 cream; bake in moderate oven until tender; serve hot.

\section{No. 23, Delicious Potatoes}

Wash and pare rather small sized potatoes; steam or boil until they can be readily pierced with a fork; dry the surplus water off; have a little butter melted in a dish, roll the potatoes in this; place in a quick oven and brown slightly; serve hot.

\section{No. 24, Hashed Potatoes}

Take cold sweet potatoes, either stamed of boiled, roasted or baked; cut into small pieces, place in a well buttered pan, mince scraps of meat of any kind and stir into it; let brown and serve hot. Chicken makes a most excellent meat to put into it.

\section{No. 25, Baked with Apples}

Take four medius-sized potatoes and the same number of apples. Wash, peel and cut the potatoes in slices about 1-4 of an inch thick; pare and slice the apples in the same way; put in baking dish in alternate layers; sprinkle 1 1-2 cups of sugar over the top, scatter 1-2 cup of butter also over the top; add 3-4 pint of hot water; bake slowly for one hour; serve steaming hot.

\section{No. 26, Sweet Potato Muffins}

Boil until thoroughly done a sweet potato weighing about 3-4 of a pound; mash very fine; pass through colander to free it from lumps; add to it a large tablespoonful of butter and a little salt; whip well; now add 1-2 cupful of milk and two well-beaten eggs, and flour enough to make a soft batter, which will be about two cupfuls. Before adding the flour sift into it one teaspoonful of baking powder. Bake in muffin or gem pans.

\section{No. 27, Sweet Potato Puffers}

Whip two eggs until quite light; two cups of cold, mashed potatoes; one cup of flour into which one teaspoon of baking powder has been sifted. The potatoes and eggs should be worked together, then the flour and baking powder; roll lightly; cut quickly, and fry in deep fat like doughnuts.

Some think a little spice improves the flavor.

\section{No. 28, Sweet Potato Savories}

Boil and mash as many sweet potatoes as required; when cold stir in sufficient flour to form into a paste; roll out and cut into small squares; seak a few bread crumbs in water for 5 or 10 minutes; squeeze dry; add a little chopped parsley, mixed herbs, and a small onion 
previously soaked in hot water; season with salt and a dash of pepper. Mix all togteher thoroughly, put a little on each square of paste, and fold over as in sausage rolls; fry in boiling fat till brown; drain and serve.

\section{No. 29, Sweet Potato Nuts}

Take one pint of boiled and mashed potatoes, one pint of toasted bread-crumbs rolled fine, one pint mixed nut meats chopped fine (peanuts are excellent); season with salt, a little pepper, also sage and mace if desired; take the yolks of two eggs; stir in two tespoons of baking powder; whip until light; pour it into the above mixture and stir well; form into small cakes; dip each into the whites of the eggs, then into shredded cocoanut, and brown in a frying pan containing a little pork fat (not deep fat); turn; brown on both sides.

\section{No. 30, Sweet Potato Riced}

Pare and boil the Potatoes in water slightly salted; when done drain off the water, and run through a ricer; serve, hot with plain or drawn butter.

The dry, mealy varieties are especially pleasing when prepared in this way.

\section{Canning}

The sweet potato is quite easy to can, and in several States the industry has assumed quite handsome proportions. They find a ready sale in localities where fresh ones cannot be had.

\section{Home Canning of Sweet Potatoes in Glass Jars}

Peel and cut the potatoes in small cubes or thick slices; pack them just as closely and firmly as possible in the jars; fill with cold water; put the lid on loosely, and boil 60 minutes; tighten the lids at once. Potatoes prepared in this way are exceedingly fine.

\section{Commercial Canning}

Mr. H. B. Benson, head of our Canning Division, and who successfully cans every year several thousand cans of potatoes, hands us the following as his method:

"The canning of sweet potatoes is not very difficult, but requires considerable attention and care, because if not handled properly an unsightly article will appear.

"There are two styles of packing, one being the whole potatoes, packed as dry as possible, the other being pie stock, in which the potatoes appear as a pulp. In packing the whole potatoes it is very necessary to keep them dry, because the nature of this vegetable is to absorb water, and they should not come from the can in a watersoaked condition. To avoid this, steam them about three-fourths 
done; slip the skins off, and pack into the cans as tightly as possible without mashing; exhaust 15 or 20 minutes; seal, and cook 3pound cans 45 minutes at 240 degrees Fahrenheit, or 90 minutes at 212 degrees Fahrenheit."

\section{As a Food for Stock}

The value of root crops for stock has so long been recognized that it is almost universally regarded as a necessity, not alone for the actual food nutrients they contain, but the peculiar diatetic effect so essential to the well-being of all animals.

A glance at the table below will convince the most skeptical of its superiority over many of the standard food-stuffs.

\section{Average Composition}

Food Material Protein, or Muscle Carbohydrates, or Fat

\section{Builders}

Mangel Beet............

Turnip ..............

Futabaga .............

Carrot ................

Parsnip

Sweet Potato ..........
1.4 per cent.

1.1 per cent.

1.2 per cent.

1.1 per cent.

1.6 per cent.

1.5 per cent.
Formers

7.6 per cent.

7.6 per cent.

9.0 per cent.

9.3 per cent.

11.4 per cent.

26.4 per cent.

We readily see that the potato contains practically as much muscle-building material as any, and more than double that of the fat formers.

In view of the above table and most espeeially the fact that years of experience has taught us that the sweet potato crop is the one that can be depended upon in favorable years for an enormous yield, which can be greatly increased with a little intelligent direction in the preparaton of the soil, fertilization, etc. We have been able to produce here on our Experiment-Station 359 bushels to the acre, and I fully believe our soils can be made to yield 500 bushels of the coaser growing varieties.

A series of experiments have proven that the Dooley Yam, Southern Queen, Pumpkin Yam and the White and Red Nansemond may be left out in the field with but slight injury for feeding purposes, which would save the expense of housing or banking and the possible large loss from decay.

\section{Experiment No. 1}

M. M. V. Darthard, in charge of the horses and mules, who personally conducted the following experiment, is enthusiastic over the results. The experiment covered a period of 30 days: 
Four mules were fed potatoes, two that were doin heavy work and two that were doing light work; corn was the grain ration. After the preliminary feeding, substitutions for grain was made at the rate of $23-4$ to 3 -1-2 pounds of potatoes to 1 1-2 pounds of corn plus the usual ration of hay.

These four mules kept in good condition, and were able to do good work. I fact, they looked as well and were able to do as much work as the four check mules..

The result of this experiment was, that the sweet potato was made to replace $1-2$ of the corn for the feeding of mules, which means a great saving in actual dollars and cents.

\section{Caution}

It is highly important that the potatoes be gradually fed in the besinning, increasing the quantity as the animal becomes accustomed to them. Frozen potatoes must also be fed with caution, or ascetic or alcoholic fermentation may set in and cause serious results. Do not feed the potatoes to horses, mules and catttle after they have become sour; hogs may eat them with safety.

Experiment No. 2-The Feeding of Sweet Potatoes to Hogs

This experiment was conducted by Mr. R. R. Robinson, in charge of the swine herd.

Six hogs were used; two were fed wholly on sweet potstoes, two were fed shorts, and two were fed corn. Eight pounds of potstoes were fed each day, with the following gain of flesh at the close of 28 dags:

Lot No. 1. Fed on potatoes; made a total gain of 24 1-2 pounds.

Lot No. 2. Fed on shorts; made total gain of 33 pounds.

Lot No. 3. Fed on corn; made a total gain of $531-2$ pounds.

These figures are intensely interesting from the fact that such highly concentrated foodstufis as shorts and corn only exceed the potatoes thus: In the matter of putting on fat-corn, 29 pounds; shorts, $81-2$ pounds. It is also easy to see that these results are not inconsistent with good farm practice, and all farmers with experience know that all kinds of stock, such as hogs, cattle, horses, mules and poultry, are not only fond of them, but thrive upon them as well, when the potatoes are judiciously fed, with concentrates, such as corn, cotton-seed meal, bran, shorts, etc.

\section{Vines}

The vines make an excellent quality of hay, which chemists find to be in composition about the same as that of succulent cow-pea vines. The vines turn black when dried, but stock eat them greedily. The vines have been found to be of the following componition: muscle builders, 12.48 per cent; fot lormers, 78.79 per cent. 


\section{Miscellaneous Information}

When potatoes are frozen so that they become soft they must be fed as fast as possible, as they will not keep.

Care must be taken not to give horses, mules and cattle too much of them, as they are very sweet after freezing and tempting to the appetite. Steaming, boiling and mixing with grains, shorts, meal, bran, corn,etc., make an excellent fattening food for hogs, and one greatly relished. We feed them after being frozen the same as before without any apparent bad results.

I have very briefly and imperfectly touched upon the many possibilities of the sweet potato. I trust that Macon County will take the lead in developing the almost limitless possibilities of this splendid crop and show its relation to the dairy industry, beef production, starch mills and that it is the most important and useful of all our root crops for the feeding of farm animals.

In 1902 Alabam produced $3,457,386$ bushels of sweet potatoes from 50,865 acres of land, a ludicrously small amount. May we not unite in all of our efforts and within a short time double that amount, and continue progressing until the maximum of production is reached. 